\title{
INTERACTION OF REINFORCED ELASTOMERIC BEARINGS IN BRIDGE CONSTRUCTION
}

\author{
L’ubica NITTMANNOVÁ ${ }^{1}$, Martin MAGURA*
}

\section{Abstract}

The aim of this paper is to demonstrate the behavior of reinforced elastomeric bearings under various loads. They are made of special types of bearings. The experimental verification of these special bearings has been tested on various types of loading. The results of the experimental measurements are compared with the results of the numerical modeling and calculations according to the standard assumptions in STN EN 1337-3. In the conclusion, the results are summarized for the selected types of bearings.

\section{Address}

1 Fire Department of Steel and Timber Structures, Faculty of Civil Engineering, Slovak University of Technology in Bratislava, e-mail: lubica.nittmannova@stuba.sk

2 Department of Steel and Timber Structures, Faculty of Civil Engineering, Slovak University of Technology in Bratislava, e-mail: martin.magura@stuba.sk

* Corresponding author: martin.magura@stuba.sk

\section{Key words}

- Bridge bearings,

- elastomer,

- modulus of elasticity,

- reinforcing plates.

\section{INTRODUCTION}

Elastomeric bearings have been used in bridge engineering since the 1960s. Nowadays, some modifications of the shape and functions of the material are taking place. The latest trends in this field are the use of carbon fiber instead of steel reinforcing plates and the use of bearings as an insulator of unwanted movements with various design modifications or various modifications to the elastomer material itself. The design and construction requirements are based on standardized relations and recommendations, which are valid only for the basic types of reinforced elastomeric bearings. Since they have begun to be used, there have been no constructional changes or adjustments.
The paper deals with the effects of reinforcements, primarily the number of elastomeric layers and their thickness.

\section{Effects of the thickness of an elastomer layer}

Fig. 1 represents the non-linear dependency of vertical deflection $\mathrm{v}_{\mathrm{z}}$ on a maximal vertical load at a constant thickness $(5,7.5,10$ and $12.5 \mathrm{~mm}$ ) of an elastomer layer. According to formula (3), the vertical deflection depends on three variable values - the effective area $A_{\text {eff }}$ the thickness of the individual elastomer layer $t_{i}$ and the shape factor S. It can be seen that an increase in the thickness of an elastomer
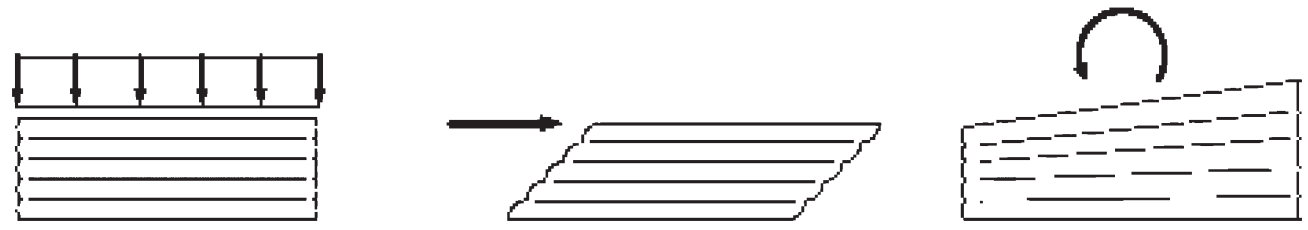

Fig. 1 The loading schemes of the bearings. 
layer results in a decreased maximal vertical load and increased vertical deflection. The maximal vertical load, maximal vertical deflection and shape factor of the bearing are given by the following formulas:

$$
\begin{gathered}
F_{z, d}=\frac{5 \cdot G \cdot A_{e f f} \cdot S}{1,5} \\
v_{z}=\sum \frac{F_{z} \cdot t_{i}}{A_{e f f}} \cdot\left(\frac{1}{5 \cdot G \cdot S^{2}}+\frac{1}{E_{b}}\right) \\
S=\frac{a_{e f f} \cdot b_{e f f}}{2 \cdot\left(a_{f f}+b_{e f f}\right) \cdot t_{E}}
\end{gathered}
$$

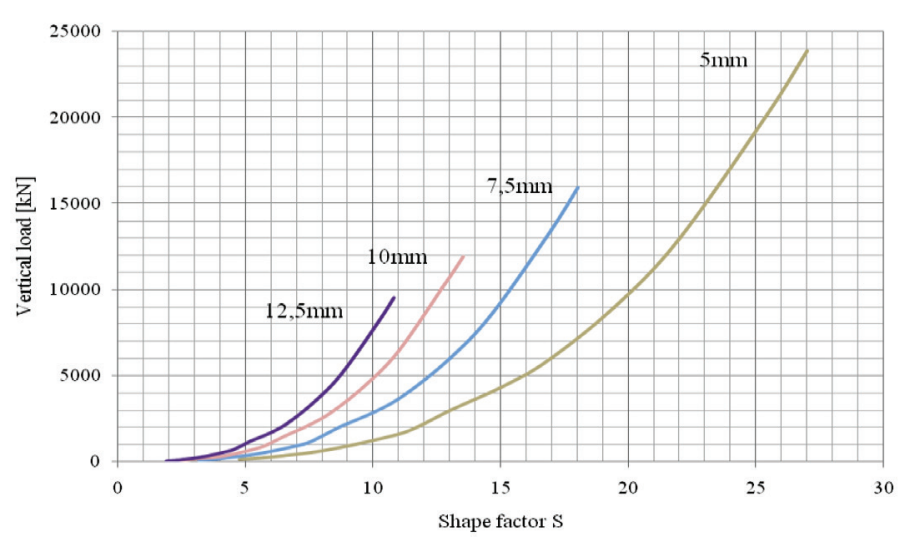

Fig. 2 Dependence of the maximal vertical load on the shape factor for thicknesses of 5, 7.5,10 and 12.5mm elastomer layers.

The graph and formulas show that the number of elastomeric layers (symbol $n_{i}$ according to EN 1337-3) does not have an influence on the allowed vertical load, vertical deflection, and shape factor. The result is that standard EN 1337-3 does not expect either nonlinear behavior of elastomeric bearings or any effect from the number of elastomeric layers on the maximal load. These effects have been verified by numerical modeling and experimental testing as seen in the next part of the work.

\section{TESTING METHODS}

Nowadays, the current STN EN 1337-3 standard recommends three methods of testing elastomeric bearings. This results from the three common most reactions, from a load-bearing structure - the vertical load, horizontal movement and rotation. These reactions are verified by the compression, shear modulus and restoring moment test methods. The bearings described in Tab. 1 and Fig. 3 were designed for the experimental verification.
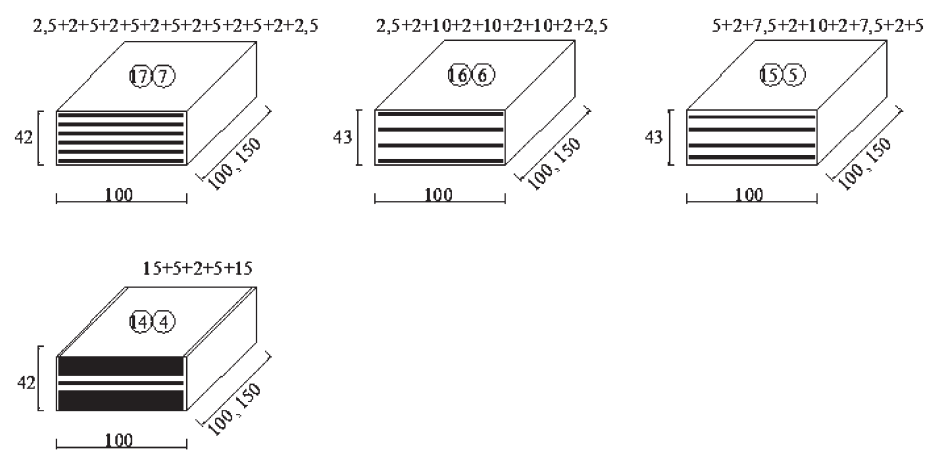

Fig. 3 Bearings designed for the experimental testing.

\subsection{Compression test method}

A compressive load occurs in every field of the application of elastomeric bearings. The deformation of the bearing is influenced by the use of reinforcing layers. The main parameters of the compressive load are the maximal vertical force, vertical deflection, and the modulus of elasticity in compression $\mathrm{E}_{\mathrm{C}}$. The test consists of measuring the compression of an elastomeric bearing when subjected to increasing compressive loads. The testing procedure specified by standard [1] is shown in Fig. 4.

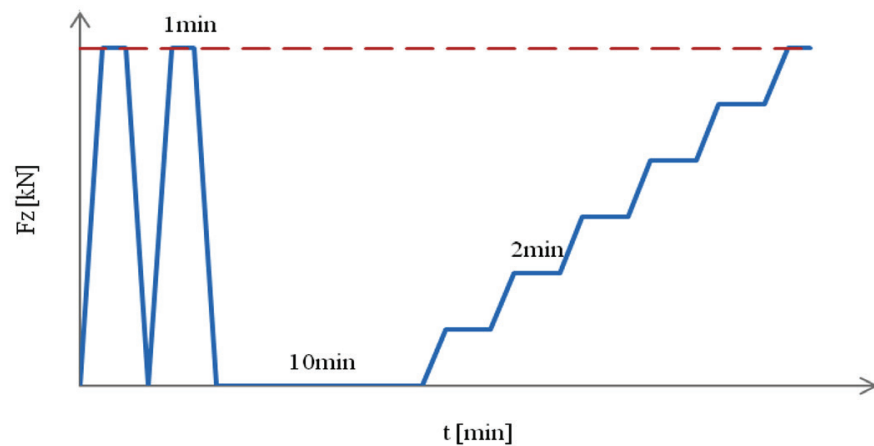

Fig. 4 Testing procedure for the first loading according to standard EN 1337-3

The standard [1] recommends three level testing procedures, where the test piece should be placed at the centre of the testing platen. The maximum load (1) should be applied to the bearing, held for $1 \mathrm{~min}$ and then removed. The recommended loading speed is 10 $\mathrm{MPa} / \mathrm{min}$. This process is repeated so that two complete loading and unloading cycles are carried out. After a further 10 min under a zero load, the next load is applied progressively with a minimum of six

\begin{tabular}{|c|c|c|c|c|c|c|c|}
\hline number & TYPE & $\mathrm{A}[\mathrm{mm}]$ & $\mathrm{B}[\mathrm{mm}]$ & $\mathrm{n}_{\text {el.layers }}$ & $\mathrm{T}_{01}[\mathrm{~mm}]$ & $\mathrm{t}_{\mathrm{E}}[\mathrm{mm}]$ & layers [mm] \\
\hline 17 & \multirow{6}{*}{1} & 100 & 100 & 5 & 42 & 5 & $2.5+2+5+2+5+2+5+2+5+2+5+2+2.5$ \\
\hline 7 & & 100 & 150 & 5 & 42 & 5 & $2.5+2+5+2+5+2+5+2+5+2+5+2+2.5$ \\
\hline 16 & & 100 & 100 & 3 & 43 & 10 & $2.5+2+10+2+10+2+10+2+2.5$ \\
\hline 6 & & 100 & 150 & 3 & 43 & 10 & $2.5+2+10+2+10+2+10+2+2.5$ \\
\hline 15 & & 100 & 100 & 3 & 43 & 7,5 & $5+2+7.5+2+10+2+7.5+2+5$ \\
\hline 5 & & 100 & 150 & 3 & 43 & 7,5 & $5+2+7.5+2+10+2+7.5+2+5$ \\
\hline 14 & \multirow{2}{*}{2} & 100 & 100 & 2 & 42 & 5 & $15+5+2+5+15$ \\
\hline 4 & & 100 & 150 & 2 & 42 & 5 & $15+5+2+5+15$ \\
\hline
\end{tabular}
increments. At each measuring point, the load is maintained at a con-

Tab. 1 Numbering of bearing and dimensions and number and thickness of layers. 

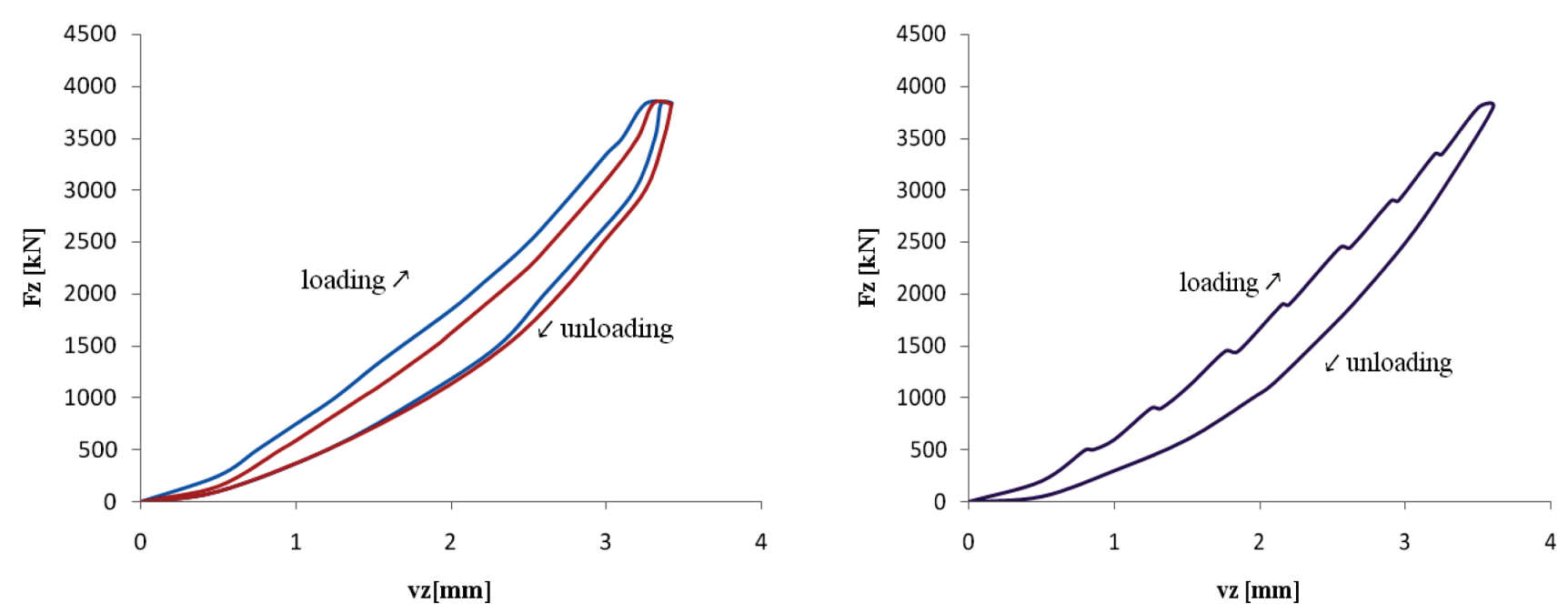

Fig. 5 Vertical deflection in first loading

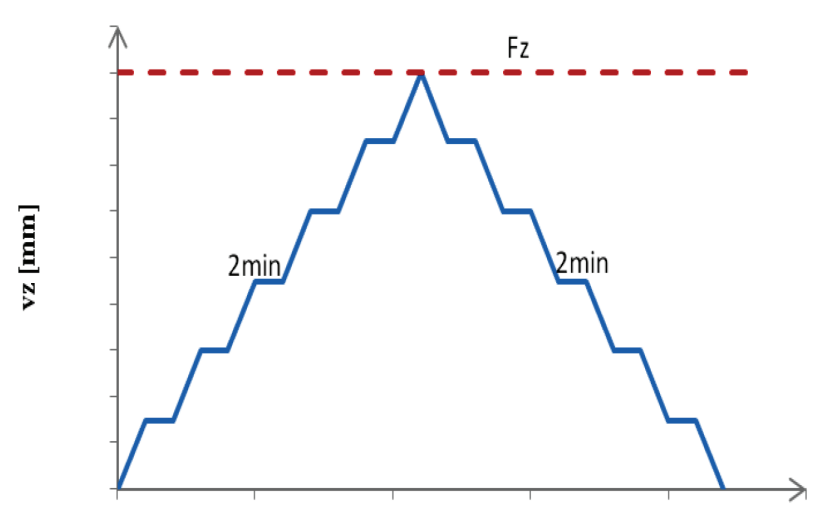

$\mathbf{t}$ [min]

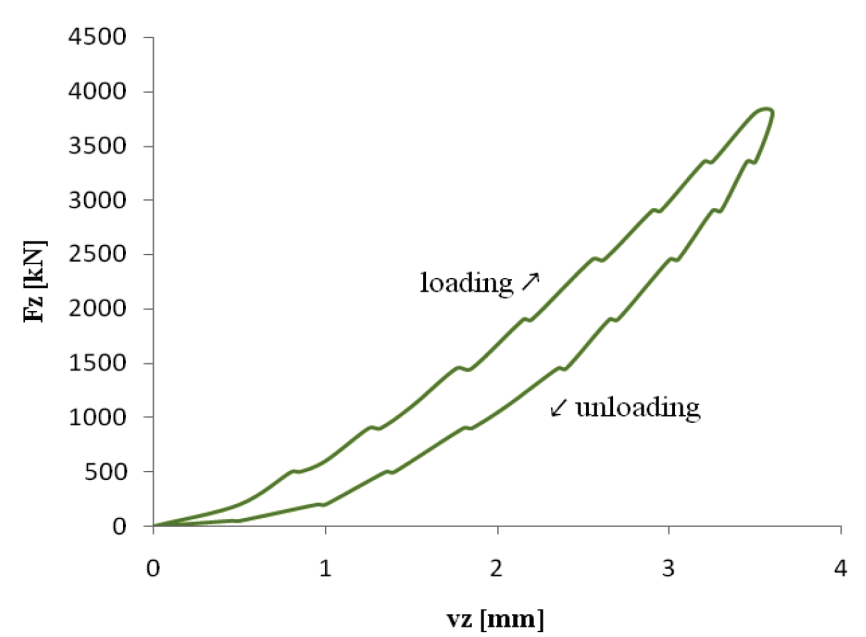

Fig. 6 Testing procedure and vertical deflection according to standard EN 1337-3 in the second loading.

stant value for a minimum 2 min. to minimize the viscoelastic effects. After the first loading, the maximum compressive load is applied progressively with a minimum of five increments at a rate of $5 \pm 0.5 \mathrm{MPa}$.

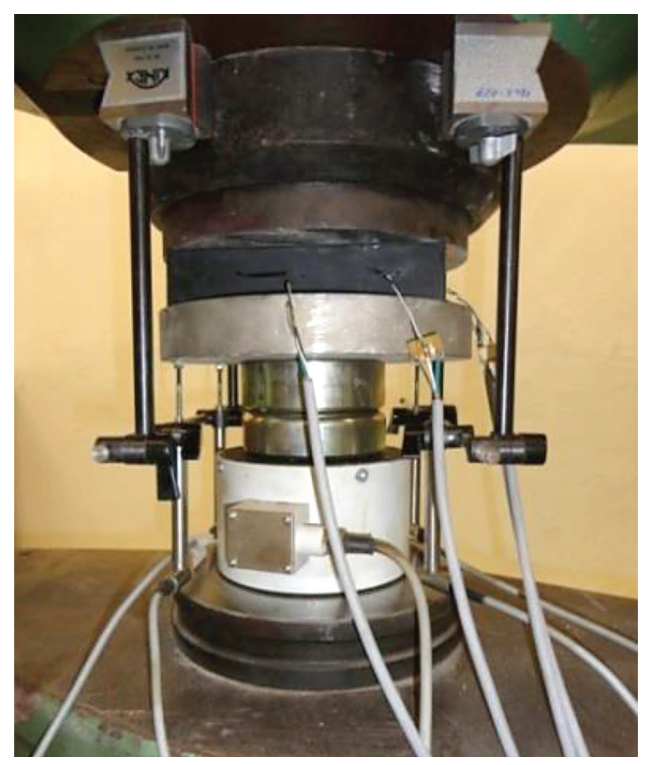

Fig. 7 Testing equipment.

\subsection{Shear modulus test method}

The test consists of measuring the shear deflection of a pair of identical bearings, when they are subjected to increasing shear loads. From these measurements, the apparent shear modulus is calculated.

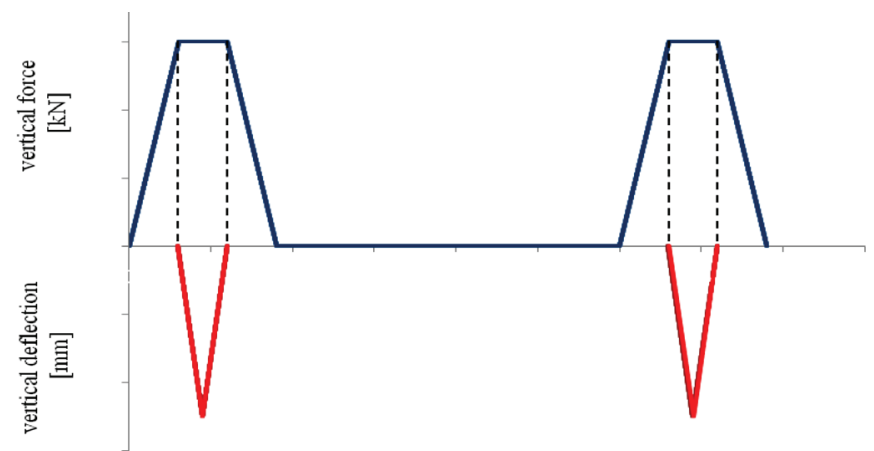

time $[\mathrm{s}]$

Fig. 8 Testing procedure for the shear modulus test method.

The test pieces should be placed symmetrically on each side of a moveable plate so that the shear direction is across the width of the bearing. A mean pressure of $6 \mathrm{MPa}$ should be applied. Then the bearings should be subjected to a shear at a constant and maximum speed 
of $150 \mathrm{~mm} /$ minute to the maximum test deflection of $80 \%$ of the total initial thickness of the elastomer $\left(\mathrm{T}_{\mathrm{e}}\right)$ and then returned to the zero deflection. The compressive load should be removed and the test pieces left undisturbed for five minutes. The cycle should then be repeated.

A conventional shear modulus is obtained from the measurement using:

$$
G_{g}=\frac{\tau_{s 2}-\tau_{s 1}}{\varepsilon_{s 2}-\varepsilon_{s 1}}
$$

$\tau_{\mathrm{s} 2} \quad$ is the shear stress and $\varepsilon_{\mathrm{s} 2}$ the shear strain at a deformation of $\mathrm{v}_{\mathrm{x} 2}=0.58 . \mathrm{T}_{\mathrm{e}}$

$\tau_{\mathrm{s} 1} \quad$ is the shear stress and $\varepsilon_{\mathrm{s} 1}$ the shear strain at a deformation of $\mathrm{v}_{\mathrm{x} 1}=0.27 . \mathrm{T}_{\mathrm{e}}$

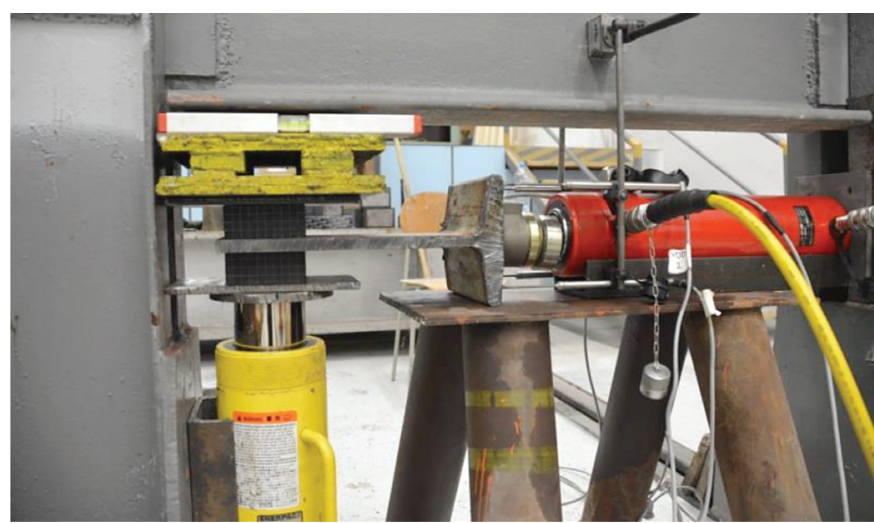

Fig.9 Testing equipment for the shear modulus.

\subsection{Restoring moment test method}

The restoring moment is defined as the moment required to rotate a bearing through a required angle. This type of load in bridge engineering is caused by a traffic load.

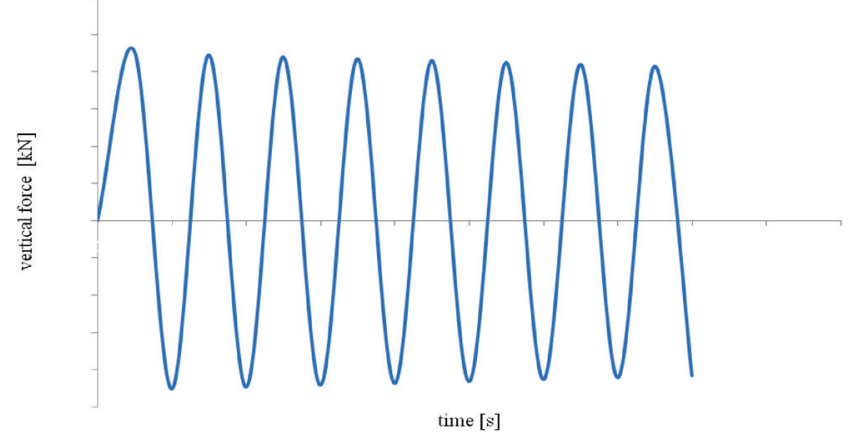

Fig. 10 Loading process

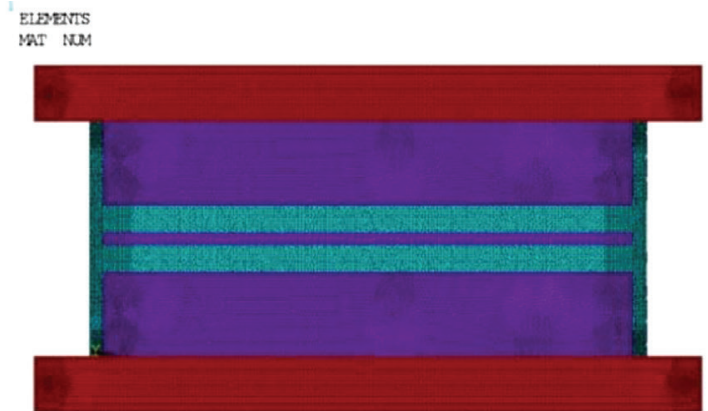

The moment is applied through a lever arm between two identical bearings. The bearing should be rotated at a specified frequency while being subjected to the specified compressive load for 10 cycles. The force on the lever arm should be recorded. The experimental value of the restoring moment is given by the expression:

$$
M_{e}=\frac{\left(F_{z 1}-F_{z 2}\right) \cdot L}{4}
$$

where:

$\mathrm{F}_{\mathrm{z} 1}$ and $\mathrm{F}_{\mathrm{z} 2}$ are the positive and negative values of the load at the tenth cycle to the lever arm, at the distance 1 from the centre of the bearing.

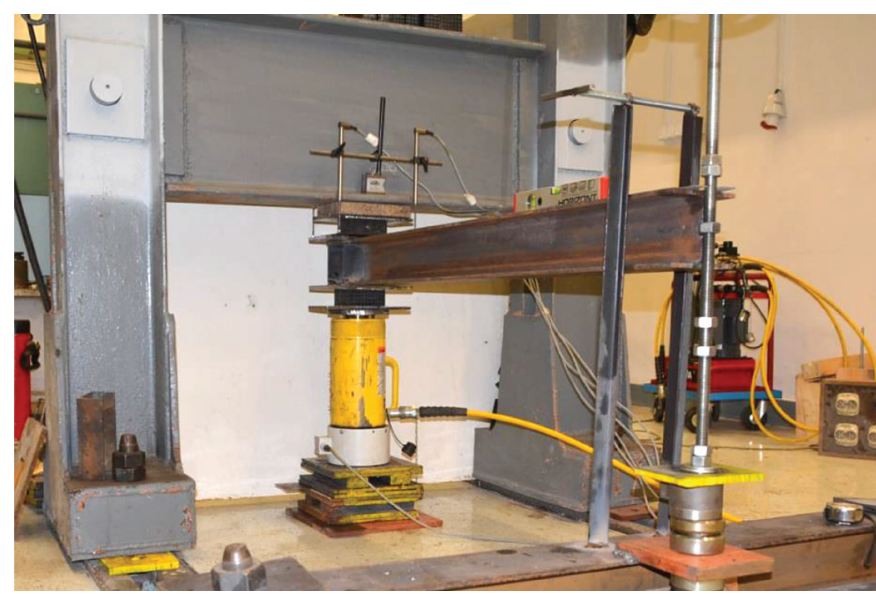

Fig. 11 Testing equipment for the restoring moment test method.

\section{NUMERICAL MODELING}

The numerical modeling was carried out using ANSYS software, which works according to the finite element method. The modeling of the individual loading case is dependent on the type of stress. For the shear modulus and restoring test methods, the parts for applying the horizontal and vertical movements (Figs. 13, 14) were modeled according to the actual testing. The bearing was built from individual layers and then the support and load were applied. Symmetry for a half bearing was used for more rapid calculations. Neo-Hook material model was used for representing the elastomer. An elasto-plastic material model with a defined working diagram from a tensile test of steel sheet was used for the steel sheet. The type of element used was a 3-dimensional, 20-node structural SOLID 186 with three degrees of freedom per node.

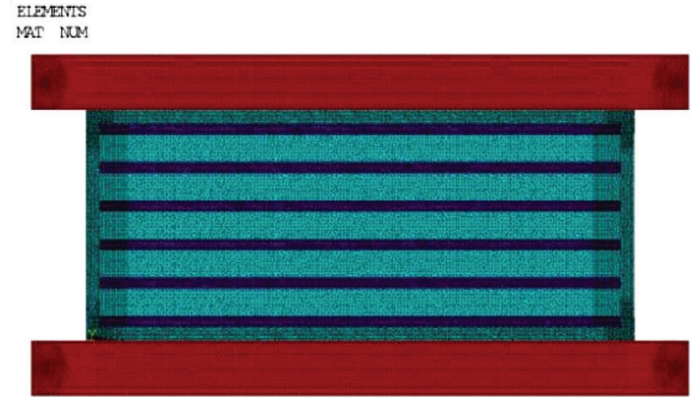

Fig.12 Numerical model for the compression test method for bearings 14 and 17 . 

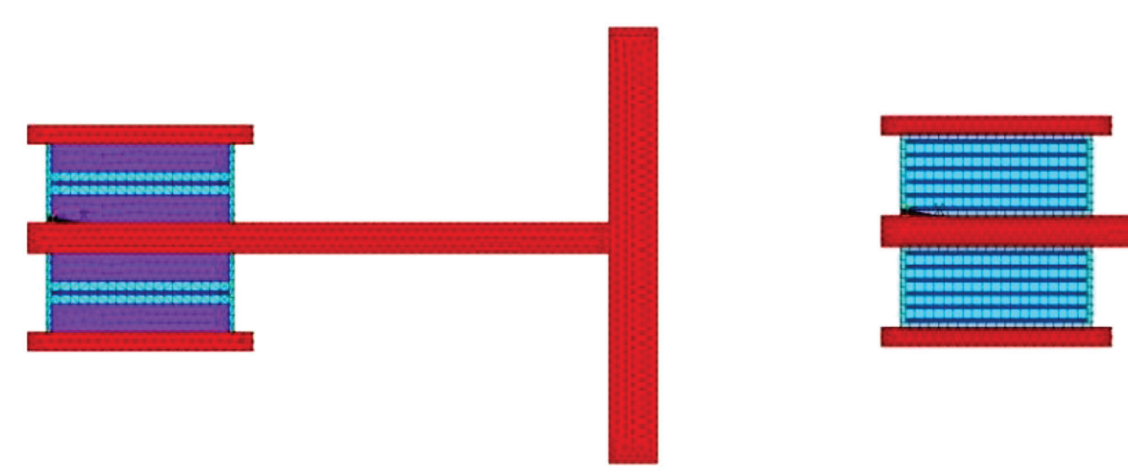

Fig. 13 Numerical model for the shear modulus test method for bearings 14 and 17.
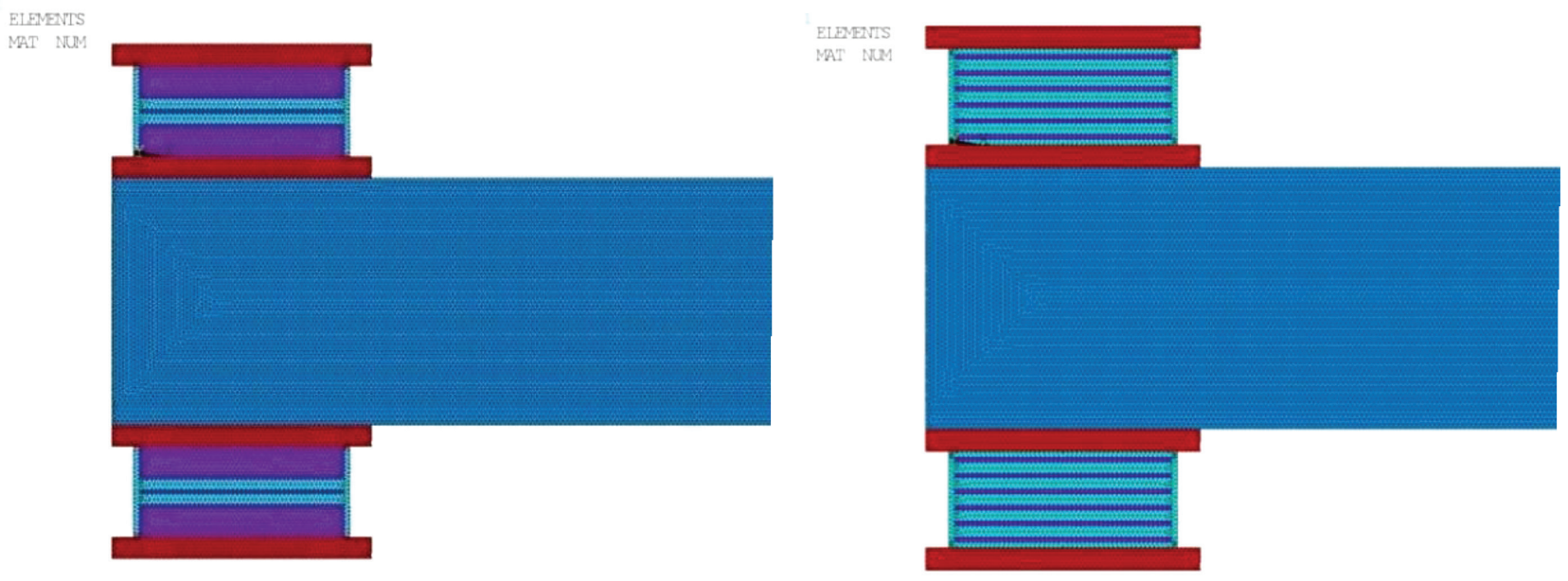

Fig. 14 Numerical model for the restoring moment test method for bearings 14 and 17 .

Tab. 2 Results from the compression test method - vertical deflection [mm].

\begin{tabular}{|c|c|c|c|c|c|c|c|c|}
\hline \multirow{2}{*}{ number } & A $[\mathrm{mm}]$ & $\mathrm{B}[\mathrm{mm}]$ & STN EN 1337-3 & \multirow{2}{*}{ ANSYS } & \multicolumn{4}{|c|}{ experimental } \\
\cline { 6 - 9 } & & & & & $1^{\text {st }}$ level & $2^{\text {nd }}$ level & $3^{\text {th }}$ level & second loading \\
\hline 17 & 100 & 100 & 3.687 & 3.427 & 3.010 & 3.015 & 3.114 & 3.249 \\
\hline 7 & 100 & 150 & 3.119 & 2.736 & 2.344 & 2.457 & 2.580 & 2.323 \\
\hline 16 & 100 & 100 & 8.528 & 4.134 & 3.377 & 3.438 & 3.555 & 3.575 \\
\hline 6 & 100 & 150 & 7.098 & 3.844 & 3.757 & 3.816 & 3.917 & 3.441 \\
\hline 15 & 100 & 100 & 7.019 & 3.92 & 4.251 & 4.48 & 4.556 & 4.435 \\
\hline 5 & 100 & 150 & 5.854 & 3.638 & 3.707 & 4.088 & 4.168 & 3.838 \\
\hline 14 & 100 & 100 & 1.475 & 1.482 & 1.489 & 1.517 & 1.549 & 1.763 \\
\hline 4 & 100 & 150 & 1.248 & 1.249 & 0.896 & 0.946 & 0.986 & 0.966 \\
\hline
\end{tabular}




\section{RESULTS}

The vertical deflection and modulus of elasticity in compression are the values resulting from the compression test method. The value of the modulus of elasticity in shear resulted, from the loading in shear and was the restoring moment from resistance to rotation. The values from the experimental testing were compared with the values according to the standard STN EN 1337-3 and the values from the numerical modeling. The bearings above the double line are from type 1, and the ones below are from type 2 (Tig.3).

Tab. 3 Results from the compression test method-modulus of elasticity in compression [MPa].

\begin{tabular}{|c|c|c|c|c|}
\hline number & $\mathrm{A}[\mathrm{mm}]$ & $\mathrm{B}[\mathrm{mm}]$ & $\mathrm{E}_{\text {C.STN EN }}$ & $\mathrm{E}_{\text {C.EXP }}$ \\
\hline 17 & 100 & 100 & 197.220 & 210.592 \\
\hline 7 & 100 & 150 & 271.634 & 278.132 \\
\hline 16 & 100 & 100 & 83.194 & 88.745 \\
\hline 6 & 100 & 150 & 99.981 & 100.851 \\
\hline 15 & 100 & 100 & 102.264 & 105.549 \\
\hline 5 & 100 & 150 & 131.838 & 132.615 \\
\hline 14 & 100 & 100 & 490.321 & 520.885 \\
\hline 4 & 100 & 150 & 749.511 & 757.682 \\
\hline
\end{tabular}

Tab. 4 Results from the shear modulus test method.

\begin{tabular}{|c|c|c|c|c|c|c|c|}
\hline number & $\mathrm{A}[\mathrm{mm}]$ & $\mathrm{B}[\mathrm{mm}]$ & $\mathrm{T}_{\mathrm{q}}[\mathrm{mm}]$ & $\mathrm{A}\left[\mathrm{mm}^{2}\right]$ & $\mathrm{G}_{\text {STN EN }}[\mathrm{MPa}]$ & $\mathrm{G}_{\text {Ansys }}[\mathrm{MPa}]$ & $\mathrm{G}_{\text {exp }}[\mathrm{MPa}]$ \\
\hline 17 & 100 & 100 & 30 & 10000 & $0.9 \pm 0.15$ & 0.97 & 1.16 \\
\hline 7 & 100 & 150 & 30 & 15000 & $0.9 \pm 0.15$ & 1.13 & 1.22 \\
\hline 16 & 100 & 100 & 35 & 10000 & $0.9 \pm 0.15$ & 0.94 & 0.98 \\
\hline 6 & 100 & 150 & 35 & 15000 & $0.9 \pm 0.15$ & 0.99 & 1.02 \\
\hline 15 & 100 & 100 & 35 & 10000 & $0.9 \pm 0.15$ & 0.87 & 0.89 \\
\hline 5 & 100 & 150 & 35 & 15000 & $0.9 \pm 0.15$ & 0.94 & 0.97 \\
\hline 14 & 100 & 100 & 10 & 10000 & $0.9 \pm 0.15$ & 1.24 & 1.32 \\
\hline 4 & 100 & 150 & 10 & 15000 & $0.9 \pm 0.15$ & 1.37 & 1.39 \\
\hline
\end{tabular}

Tab. 5 Results from the restoring moment test method.

\begin{tabular}{|c|c|c|c|c|c|}
\hline number & $\sigma_{\mathrm{z}}[\mathrm{MPa}]$ & $\alpha[\%]$ & $\begin{array}{l}M_{\text {STN EN }} \\
{[\mathrm{kNm}]}\end{array}$ & $\begin{array}{l}\mathrm{M}_{\text {ANSYS }} \\
{[\mathrm{kNm}]}\end{array}$ & $\mathrm{M}_{\mathrm{exp}}[\mathrm{kNm}]$ \\
\hline 17 & \multirow{8}{*}{7} & \multirow{8}{*}{3} & 0.037 & 0.101 & 0.122 \\
\hline 7 & & & 0.064 & 0.093 & 0.139 \\
\hline 16 & & & 0.008 & 0.031 & 0.089 \\
\hline 6 & & & 0.013 & 0.055 & 0.076 \\
\hline 15 & & & 0.018 & 0.074 & 0.119 \\
\hline 5 & & & 0.032 & 0.077 & 0.079 \\
\hline 14 & & & 0.092 & 0.144 & 0.178 \\
\hline 4 & & & 0.161 & 0.181 & 0.195 \\
\hline
\end{tabular}

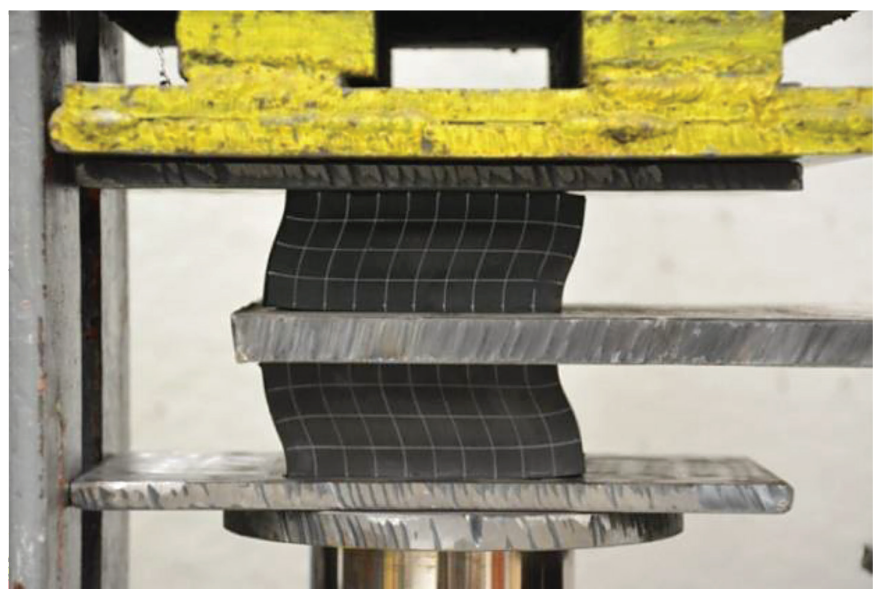

Fig. 16 Bearing under a shear load.
The photos below provide a better illustration of the behavior of the bearings according to the various testing methods.

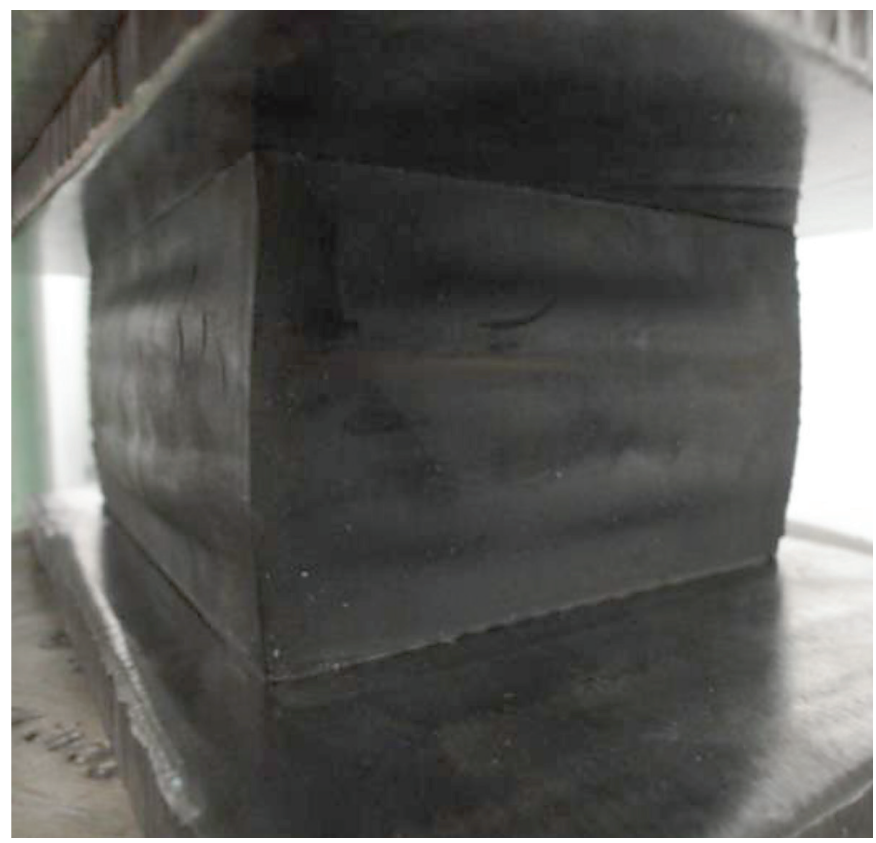

Fig. 15 Bearing under a compressive load. 


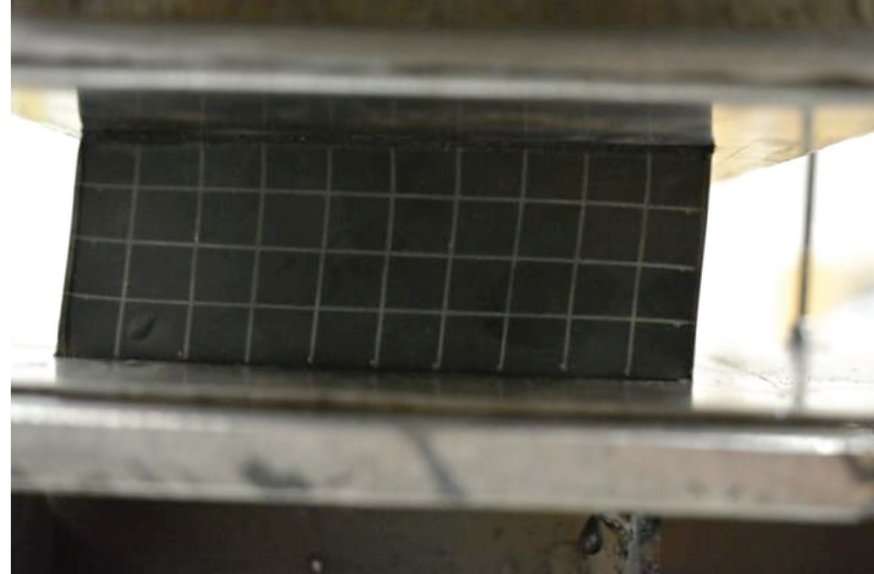

Fig. 17 Bearing under a bending moment load.

\section{CONCLUSION}

The aim of this paper was to demonstrate the behavior of reinforced elastomeric bearings under various loading types. Experimental testing was carried out to verify the interaction of reinforced elastomeric bearings in bridge construction. The resulting values of the parameters obtained were compared with the values from the numerical modeling by FEM and the values estimated from stand- ard STN EN 1337-3. The values from the numerical modeling were almost always between the other two methods. In the experimental testing the resulting values of the vertical deflection from the compression test method were on the safe side (the expected number of bearings were $5.14,15)$. The values calculated according to standard [1] were higher, so this part of the standard also indicates the correct assumption. For the calculation of the values of the modulus of elasticity in compression, the standard also indicates the correct assumption. The resulting values of the shear modulus from the experimental testing and numerical modeling were always higher than the standard assumed. The most important indicator was the behavior of the reinforced bearings under the moment load test. The values of the restoring moment from the experimental testing and numerical modeling were much higher than those calculated by the standard. The main reason for this difference is the independence of the restoring moment from the amount of the compressive stress. The second reason was an assumption of the linear behavior of the bearings under all types of loads according to the standard, which proved to be incorrect. Other reasons could be inaccurate measurements or a simplified load system. On the other hand, these results are in accord with those from the numerical modeling. The formulas in the standard should be modified by the results from the experimental studies, but that could be expensive. In a comparison of the two types of bearings the higher difference is only shown by the compressive testing method. The vertical deflections of bearing type 1 are two times higher than those of type 2, due to the outer steel plates with a thickness of $15 \mathrm{~mm}$, which increases the vertical stiffness of the bearing.

\section{REFERENCES}

STN EN 1337-3 (2005) Structural bearings-Part 3: Elastomeric bearings. SUTN

STN EN 10002-1 (2002) Metal materials - Tensile testing. Part 1 : Tensile test at room temperature. Slovak standard institute

Block, T. (2010). Verdrehwiderstände bewehrter Elastomerlager. Bochum

Eggert, H. (2006) Bewehrte Elastomerlager. Erkenntnisstand und Defizite. Bautechnik

Nittmannová, L. (2015) Compressive load of elastomeric bearings. Juniorstav 2015, 17. The International Conference of Postgraduate Students. Brno

Nittmannová, L. - MAGURA, M. (2014) Effect of Reinforcement in Elastomeric Bearings under Compressive Load. The International Masaryk Conference: prceedings $1^{\text {st }}$ edition, Hradec Králové : Magnanimitas. 2014. online. pp. 3754-3759. ISBN 978-8087952-07-8

Nittmannová, L. (2012) Sliding parts of bridge bearings. In Procedia Engineering: Steel Structures and Bridge 2012. Czech and Slovak International Conference.Podbanské.SR.26. - 28.9.2012. Vol. 40 (2012). pp. 328-332. ISSN 1877-7058.
Petersen, Ch. (1987) Zur Beanspruchung moderner Brückenlager-Eine Parameterstudie. Festschrift J. Scheer. Braunschweig

\section{ANSYS Help}

Topaloff, B. Gummilager für Brücken - Berechnung und Anwendung. Der Bauingenieur 39, pp. 50-64

Hermann, L. R. - Haimdl, R. - Shafigh - Nobard F., Ramaswamy A. (1988) Nonlinear Behavior of Elastomeric Bearings. II: FE Analysis And Verification. Journal of Engineering Mechanics, Volume 114, Issue 11, November

Hubinská, L. (2008) Real behaviour of bridge filler beam deck. Juniorstav 2008 : 10th Professional Conference of Postgraduate Students : Brno University of Technology. Faculty of Civil Engineering. ISBN 978-80-86433-45-5.

DIN 4141(1984): Lager im Bauwesen. Beuth Verlag GmbH. Berlín

Kaiser, J. - Složka, V. - Dický, J. - Jurasov, V. (1990) Elasticity and Plasticity. Bratislava. Alfa. 